\title{
A difícil interface controle de vetores - atenção básica: inserção dos agentes de controle de vetores da dengue junto às equipes de saúde das unidades básicas no município de São José do Rio Preto, SP
}

The difficult interface between vector control and primary care: insertion of dengue fever vector control agents into health teams at the primary health centers in São José do Rio Preto, São Paulo, Brazil

\author{
Marisa Bernardi Cesarino \\ Médica Veterinária. Mestre em Ciências da Saúde. \\ Endereço: Rua Raul Silva, 454, Bairro Redentora, CEP 15015-020, \\ São José do Rio Preto, SP, Brasil. \\ E-mail: marisacesarino®yahoo.com.br \\ Margareth Regina Dibo \\ Doutor em Ciências da Saúde. Pesquisador Científico IV na Su- \\ perintendência de Controle de Endemias - SUCEN. Professor da \\ Faculdade de Medicina de São José do Rio Preto. \\ Endereço: Av. Brigadeiro Faria Lima, 5416, CEP 15090-000, São José \\ do Rio Preto, SP, Brasil. \\ E-mail: medibo®famerp.br

\section{Aurea Maria Zöllner Ianni} \\ Livre-Docente. Professora da Faculdade de Saúde Pública da \\ Universidade de São Paulo. \\ Endereço: Av. Dr. Arnaldo, 715, Cerqueira Cesar, CEP 01246-904, \\ São Paulo, SP, Brasil. \\ E-mail: aureanniळusp.br

\section{Maria Elenice Vicentini} \\ Enfermeira. Especialista em Saúde Publica e no Gerenciamento de \\ Unidades de Saúde no SUS. Enfermeira na Vigilância Sanitária da \\ GVS XXIX / Secretária de Estado da Saúde de São Paulo. \\ Endereço: Rua das Palmeiras, 5400, Jd. Sta. Catarina, CEP 15080- \\ 100, São José do Rio Preto, SP, Brasil. \\ E-mail: elen.vicentiniळhotmail.com
}

\author{
Amena Alcântara Ferraz \\ Bióloga. Doutoranda em Ciências da Saúde pela Faculdade de \\ Medicina de São José do Rio Preto. Técnica de planejamento em \\ Saúde na Secretaria Municipal da Saúde de São José do Rio Preto. \\ Endereço: Rua Romeu Strazz, 199, Vila Sinibaldi, CEP 15084-010, \\ São José do Rio Preto, SP, Brasil. \\ E-mail: amenaferrazœyahoo.com.br \\ Francisco Chiaravalloti-Neto \\ Livre-Docente. Professor da Faculdade de Saúde Pública da Uni- \\ versidade de São Paulo. \\ Endereço: Av. Dr. Arnaldo, 715, Cerqueira Cesar, CEP 01246-904, \\ São Paulo, SP, Brasil. \\ E-mail: franciscochiara®usp.br
}




\section{Resumo}

Este estudo analisa o processo de inserção dos agentes de controle de vetores nas unidades básicas de saúde (UBS) em São José do Rio Preto-SP, designados agentes de saúde (AS), com o objetivo de melhorar a eficácia do programa de controle da dengue. Trata-se de um estudo de caso, baseado na observação direta e no registro das falas dos participantes de fóruns promovidos pela Secretária de Saúde do município com esses profissionais. Realizou-se a análise de conteúdo desses registros, identificando-se cinco categorias: inserção social; integralidade da atenção; intersetorialidade; valorização dos AS; e educação permanente. Os profissionais expressaram a necessidade dos fóruns de discussão serem permanentes; as dificuldades para realizar ações intersetoriais; e o sentimento de valorização profissional por participar das equipes das UBS e por colaborar com a participação comunitária. 0 estudo possibilitou compreender como ocorreu a inserção dos AS na atenção básica do município e a complexidade do controle da dengue nesse nível de atenção, que envolve questões socioambientais e ações intersetoriais. $\mathrm{O}$ estudo revelou as diversas possibilidades de atuação dos AS e a pertinência da sua inserção na atenção básica.

Palavras-chave: Dengue; Agente de Controle de Vetores; Educação em Saúde; Atenção Básica; Sistema Único de Saúde.

\section{Abstract}

This study analyzes the insertion process of vector control agents into the primary health centers (PHCs) in São José do Rio Preto, São Paulo, Brazil, designated health workers (HWs), in order to improve the effectiveness of the dengue fever control program. This is a case study, based on direct observation and recording of participants' speeches in forums held by the municipal Secretary of Health with these professionals. These records underwent content analysis, and five categories were identified: social insertion; comprehensiveness of care; intersectoriality; appreciation of HW; and continuing education. The professionals expressed the need for permanent discussion forums; the difficulties to take intersectoral actions; and the feeling of professional appreciation for participating in teams from PHCs and collaborating to community participation. The study allowed us to understand how the insertion of HWs took place in municipal primary care and the complexity of dengue fever control, at this level of care, which involves socio-environmental issues and intersectoral action. The study revealed the various possibilities of action for HWs and the relevance of their insertion into primary care.

Keywords: Dengue Fever; Vector Control Agent; Health Education; Primary Care; Unified Health System. 


\section{Introdução}

No Brasil o combate a Aedes aegypti foi institucionalizado no século XIX, quando epidemias de febre amarela urbana e de dengue ocorriam no país. Desde então, o seu controle passou por diversas e diferentes abordagens na perspectiva da erradicação do vetor, que foi alcançada em 1957 e mantida até 1967, quando ocorreu a reintrodução do mosquito em território nacional. Nova tentativa de erradicação foi proposta com a criação do Programa de Erradicação de Aedes aegytpi (PEAa), em 1996, que tinha o objetivo de combinar as práticas e conceitos da erradicação com a política da descentralização preconizada pelo Sistema Único de Saúde (SUS) (Brasil, 2001).

A implantação do PEAa resultou em um fortalecimento das ações de combate ao vetor, com significativo aumento de recursos para essas atividades, mas manteve a gestão centralizada e verticalizada e a prestação de serviços permaneceu segmentada por procedimentos e equipes específicas para cada doença (Brasil, 2001). Foram mantidas as ações de prevenção centradas quase que exclusivamente nas atividades de campo de combate ao mosquito com o uso de inseticidas, estratégia comum aos programas de doenças cujos agentes são transmitidos por vetor em todo o mundo; uma prática que se mostrou ineficaz e absolutamente incapaz de responder à complexidade epidemiológica da dengue (Brasil, 2001).

Como resposta à ineficácia do PEAa, o Ministério da Saúde (MS) estabeleceu, em 2002, o Programa Nacional de Controle da Dengue (PNCD), incorporando mudanças como a elaboração de um programa de controle permanente, desenvolvimento de campanhas de informação e mobilização da população, fortalecimento da vigilância epidemiológica e entomológica, melhoria da qualidade do trabalho de campo e integração das ações de controle da dengue às atividades desenvolvidas pelo Programa de Agentes Comunitários de Saúde/Programa de Saúde da Família (PACS/PSF). O PNCD também preconiza a utilização de instrumentos legais que facilitem a eliminação de criadouros, atuação multissetorial quanto ao destino de resíduos sólidos e recipientes seguros para armazenamento de água, desenvolvimento de instrumentos mais eficazes de acompanhamento e supervisão das ações desenvolvidas pelo MS e pelas Secretarias de Saúde dos Estados e municípios (Brasil, 2002).

Apesar dos avanços do PNCD em relação ao PEAa, na prática, as características verticalizadas do programa de combate ao vetor persistem, acarretando problemas como a pouca articulação das ações de prevenção e controle com as demais iniciativas programáticas do SUS, resultando em ações ineficientes e no não cumprimento das metas do programa, muitas delas infactíveis (Penna, 2003).

Esses problemas, somados à falta de fluxos para os encaminhamentos de demandas a outros setores além da saúde (intersetorialidade), tornam a dengue um dos desafios atuais para saúde pública, classificada como uma das principais endemias brasileiras, com elevado número de pessoas acometidas todos os anos e aumento do risco de ocorrência de casos graves e óbitos (Brasil, 1996; Machado e Porto, 2003; Penna, 2003; Santos, 2003; Lima e Vilasbôas, 2011).

Em São José do Rio Preto, São Paulo, a dengue é considerada endêmica desde 2000 (Mondini e col., 2005), quadro que exigiu da Secretaria Municipal de Saúde (SMS) uma reflexão sobre a efetividade das medidas atualmente preconizadas para o controle do vetor Aedes aegypti, em especial as atividades desenvolvidas pelos agentes de controle de vetores (ACV). A cidade tem sido objeto de pesquisas na busca de respostas a esses problemas, como a realizada entre 2001 e 2003 (Chiaravalloti-Neto e col., 2006), que mostrou que as atividades de controle desenvolvidas pelos agentes comunitários de saúde (ACS) com base na Estratégia da Saúde da Família (ESF) foram tão efetivas quanto às executadas pelos ACV, apresentando ganhos em relação à participação da comunidade no controle vetorial. Outro resultado da pesquisa foi a constatação de que a população reconhecia o ACV como o seu interlocutor para as reclamações e demandas em geral, chegando a requerer a solução de problemas que iam além da presença do vetor e da doença (Chiaravalloti e col., 2002).

Chiaravalloti-Neto e colaboradores (2007) também identificaram dificuldades na atuação dos ACV e na adesão da população ao PNCD. A população referia que o controle e a prevenção da dengue seriam atividades de importância menor, cabendo ao agente encaminhar todas as demandas e queixas aos serviços de saúde, sem restringir-se àquelas 
relacionadas à dengue. Os ACV, por seu lado, apontaram recusas da população às visitas domiciliares, a falta de adesão ao programa e a diferenciação do valor atribuído ao seu trabalho em relação aos ACS integrados às unidades básicas de saúde da família (UBSF), que tinham seu trabalho considerado, pelos ACV, como de maior status.

Os autores observaram entre mulheres moradoras a culpabilização sobre a higiene doméstica como a causa da presença do vetor e queixas sobre a falta de estrutura na coleta de lixo, bem como condições precárias de saneamento urbano. Concluíram que percepções negativas sobre a atuação dos ACV decorriam, principalmente, da característica vertical do programa de controle da dengue, e, para minimizar ou solucionar esses problemas, sugeriram a incorporação dos ACV às unidades básicas de saúde, um maior investimento nas ações intersetoriais e o desenvolvimento de estratégias programáticas intersetoriais para que os ACV viessem a atuar sobre as condições ambientais no município.

Com base nesse diagnóstico, e num novo contexto de mudança da gestão municipal em São José do Rio Preto, desencadeou-se no ano de 2001 uma reorganização do sistema local de saúde que envolveu uma nova lógica de organização das atividades de controle da dengue, com a inserção dos ACV na atenção básica, tendo em vista o aumento da efetividade do controle da dengue. Essa reorganização do sistema representou uma mudança na política de saúde pública municipal, que pressupunha, para ser efetivada, o apoio não só da equipe gestora da SMS como das equipes gestoras e profissionais das UBS.

A inserção dos ACV na atenção básica do município, agora denominados agentes de saúde (AS), provocou, no entanto, conflitos e desconfortos, uma vez que as equipes das unidades básicas de saúde trabalhavam num modelo de atenção pouco permeável ao novo profissional, cujas atribuições, desconhecidas até então por essas equipes, foram interpretadas como mais um problema somado à gama dos já existentes.

Constatando essas dificuldades, a equipe gestora da SMS buscou apoio de coordenadores de outros programas, na perspectiva de equacionar os conflitos decorrentes da inserção dos AS (ex-ACV) nas UBS. A complexidade da situação e a diversidade de profissionais envolvidos mostrou a necessidade de implementar um processo de diálogo ampliado educação permanente - no qual as soluções fossem buscadas em conjunto, e que envolvesse os AS, seus supervisores e os profissionais da unidade de saúde. A estratégia escolhida para a efetivação desse processo de educação permanente foi a realização de fóruns de discussão intrassetoriais.

\section{Os fóruns de discussão: aprendizagem e troca de experiências}

Os fóruns eram realizados em dois momentos distintos: concentração e dispersão. A concentração ocorria trimestralmente e os profissionais eram divididos em grupos que se reuniam em roda de conversa, em diferentes datas e em locais distintos do trabalho. Eram ao todo sete grupos com representantes de vários profissionais da atenção básica - AS, ACS, supervisores, enfermeiros, psicólogos e assistentes sociais - e alguns facilitadores das discussões. No período de 2006 a 2009 foram realizados 16 fóruns, com aproximadamente 110 atividades de concentração e dispersão.

Nas atividades de concentração utilizou-se o método da problematização, partindo-se da realidade dos integrantes (Freire, 200o), enquanto os temas eram relacionados a questões do processo de trabalho; uma forma que proporcionava uma relação horizontal de discussão entre os profissionais.

A coordenadora da estratégia da saúde da família à época, em conjunto com uma psicóloga com experiência em trabalho de grupo e conhecimento da ESF, além de uma das autoras deste estudo (MBC), desempenharam o papel de facilitadoras; a perspectiva foi de estimular os profissionais a recuperarem suas experiências prévias, possibilitando que falassem sobre o seu trabalho, que conhecem profundamente, tornando-se sujeitos do processo de ensino-aprendizagem (Freire, 2003). Ao final de cada concentração definiam-se as tarefas a serem executadas pelos profissionais nas suas UBS e UBSF. Esse momento correspondia à dispersão, cujos resultados eram relatados na próxima concentração.

Em média, a duração de cada momento de concentração era de oito horas, durante as quais eram desenvolvidas as seguintes atividades: 
a) Lian Gong: prática chinesa de exercícios terapêuticos que promove o autoconhecimento do corpo estimulando o autocuidado e a responsabilidade sobre a saúde individual e coletiva ${ }^{1}$.

b) Espaço aberto: momento em que os profissionais discutiam sua condição de trabalho, problemas, dúvidas, limites, possibilidades e questões trabalhistas, entre outras. Suas falas eram registradas em flip chart e discutidas. Quando possível, as questões recebiam resposta imediata, quando não, eram encaminhadas para a equipe gestora da SMS e respondidas conforme o grau de urgência.

c) Apresentação dos resultados da dispersão: a cada fórum, um relator de cada unidade básica de saúde era escolhido para a apresentação. $\mathrm{Na}$ sequência, as facilitadoras estimulavam as discussões, que abordavam aspectos relativos ao compromisso dos profissionais com o trabalho, o envolvimento com a equipe e o planejamento das ações propostas. 0 diálogo sobre as situações-problema, a troca de experiência e a horizontalidade da discussão propiciava um clima de integração, abrindo espaço para a construção e implementação de uma nova realidade de trabalho.

d) Discussão dos temas: a cada concentração escolhia-se um tema específico, acordado junto aos profissionais e facilitadores no fórum anterior. Os temas eram escolhidos considerando a política municipal de saúde vigente e conforme as metas definidas no planejamento anual da saúde para o município. Além da troca de experiência entre os participantes, essa atividade visava fortalecer as equipes de trabalho e discutir os resultados a serem alcançados.

e) Definição e orientação para o desenvolvimento da atividade de dispersão.

f) Avaliação da concentração: em plenária, os participantes manifestavam sua opinião sobre a atividade do fórum, como o deslocamento, o local, a alimentação, os conteúdos discutidos e as dinâmicas utilizadas, entre outras.

Os fóruns constituíram-se um espaço de discussão que permitiu aos profissionais de saúde, em especial aos AS, refletirem sobre a sua atuação enquanto sujeitos do processo de trabalho (Barban e Oliveira, 2007). Eles passaram a se ver como profissionais que, a partir das visitas domiciliares, seriam capazes de intervir nas situações identificadas e de levar às UBS sua posição, tanto de profissional da saúde como de morador da comunidade. Os AS eram os únicos profissionais da equipe de saúde da atenção básica que não tinham formação anterior na área, e os fóruns ofereceram essa oportunidade por meio de troca de experiências entre eles e as diferentes unidades de saúde, além da discussão sobre organização do processo de trabalho (Estrela, 2010). Os fóruns permitiram que eles expusessem as suas percepções sobre o processo de trabalho, fazendo-os perceber que todos tinham experiências bem-sucedidas e dificuldades semelhantes na realização de atividades nos seus territórios, o que os colocava em uma relação de iguais diante dos demais profissionais da atenção básica.

A proposição dos fóruns como estratégia de articulação dos profissionais, de visibilização de problemas ou dificuldades da prática do trabalho e identificação e promoção de soluções tem exemplos na área de saúde. A literatura mostra que esse dispositivo de gestão foi utilizado na formação de médicos homeopatas para o SUS (Estrela, 2010), na discussão sobre o cuidado ao pé diabético (Evangelista e col., 1999) e na educação permanente de profissionais de saúde na atenção básica (Barban e Oliveira, 2007).

Com base nas informações registradas durante a realização dos fóruns, neste trabalho objetivou-se analisar o processo de inserção dos agentes de controle de vetores, renomeados de agentes de saúde, nas unidades básicas de saúde do município de São José do Rio Preto, SP.

\section{Procedimentos metodológicos}

Este estudo de caso foi realizado em São José do Rio Preto, município situado a Noroeste do estado de São Paulo, com 408.258 habitantes, em 2010; de clima quente e sede de região do Estado, reúne 102 cidades.

A primeira ocorrência de dengue na cidade deu-se

1 Atividades físicas foram incorporadas pelo MS através da Política Nacional de Promoção à Saúde (Portaria nº 687 MS/GM - 30 de março de 2006). Essa atividade ocorria no início da concentração e era coordenada, em rodízio, por um agente (AS ou ACS). 
em 1990, sendo atualmente endêmica para a doença (Mondini e col., 2005), com circulação dos quatro sorotipos do vírus.

O universo de estudo constituiu-se dos profissionais de saúde que participaram dos fóruns, envolvendo 23 unidades de atenção básica, das quais 14 UBS em que houve a inserção dos ACV, e 9 UBSF. Organizados pela SMS, os fóruns ocorreram no período 2006 a 2009 , tendo sido registrados sistematicamente e na íntegra, o que permitiu a inclusão das discussões neles realizadas e as falas dos membros participantes.

A assinatura do termo de consentimento livre e esclarecido foi providenciada para fins de ética do procedimento de pesquisa (Parecer 436/20o6), tendo participado do estudo 25 enfermeiros, 6 psicólogos, 6 assistentes sociais, 248 agentes (ACS e AS) e 15 supervisores.

A análise dos registros foi realizada pelo método de análise de conteúdo categorial de Bardin (1977), que constitui um conjunto de técnicas que visam obter, por meio de procedimentos sistemáticos e objetivos de descrição do conteúdo das mensagens, indicadores quantitativos ou não que permitam a inferência de conhecimentos relativos às condições de produção, emissão e recepção das mensagens contidas nos discursos dos sujeitos; neste caso, as falas dos profissionais participantes dos fóruns. A análise de conteúdo possibilita a compreensão do que está por trás das palavras, permitindo identificar outras realidades através das mensagens emitidas pelos sujeitos da pesquisa.

Segundo Bardin (1977), o tema, ou conteúdo, é uma unidade de significação que se liberta naturalmente de um texto analisado, de acordo com certos critérios relativos à teoria que serve de guia. Explica a autora que podem ser feitos recortes dos textos em ideias constituintes, em enunciados e em proposições portadoras de significados isoláveis. O tema é utilizado como unidade de registro para estudo de diversos aspectos, tais como a motivação de opiniões, de atitudes, de valores, de crenças e de tendências.

As etapas de análise dos dados corresponderam a:

1) organização dos registros realizados durante os fóruns;

2) organização e estudo exploratório do material;
3) codificação dos temas: identificaram-se os temas recorrentes nos registros das falas dos profissionais. Procedeu-se, então, uma codificação da representação temática dos seus conteúdos, redunando nas cinco categorias apresentadas nos resultados (Bardin, 1977). A identificação dos temas foi feita considerando-se as diretrizes e as normas técnicas da Superintendência de Controle de Endemias (Sucen), órgão vinculado à Secretaria de Estado da Saúde de São Paulo, e do MS, no tocante ao controle de vetores; e do MS, no que se refere à atenção básica e ao trabalho realizado pelo ACS (Sucen, 2001; Brasil, 2002; Chiaravalloti-Neto e col., 2006).

\section{Resultados e discussão}

A análise das falas dos participantes dos fóruns permitiu identificar cinco categorias: inserção social; integralidade; intersetorialidade; valorização dos AS; e educação permanente. Elas serão apresentadas e discutidas nessa ordem.

\section{Inserção social}

Nas normas da Sucen, de caráter técnico, o território é uma área geográfica cuja estratificação viabiliza a realização das avaliações entomológica e epidemiológica e o planejamento das ações de controle da dengue, devendo-se cadastrar e classificar os imóveis de maior importância para a dispersão do vetor e para a disseminação do vírus da dengue (Sucen, 2001). Para o MS, numa visão mais ampla, o território não é apenas uma área geográfica, mas um espaço, produto de uma dinâmica social em permanente construção, no qual os indivíduos se encontram em constante conflito de interesses, de projetos e de sonhos (APM, 2001).

Nos fóruns, os participantes apresentaram seus relatos referentes ao território, e a situações vivenciadas na rotina de trabalho após a inserção nas UBS: conheço detalhes, esse bairro é meu, tenho comprometimento; conheci pessoas que só se via circulando; ocorreu a apropriação do território da área de abrangência da UBS pelo agente; desenvolvemos olhar crítico para outros problemas de saúde além da dengue. Essas falas revelam uma percepção 
dinâmica do território pelos agentes de saúde e a arguta captação das informações e conhecimentos de situações relevantes para o desenvolvimento de suas atividades diárias.

Segundo as normas técnicas da Sucen, quando das visitas realizadas aos moradores, o agente deve observar o ambiente da casa e de seus arredores, procedendo às recomendações necessárias para o controle do vetor. Para o órgão, durante a execução dos procedimentos de controle, é importante que o agente oriente e realize a conduta para o controle mecânico, ou seja, a eliminação ou mudança de local do recipiente para que ele deixe de ser criadouro, e/ ou uso de produtos alternativos (sal e água sanitária) para o controle de criadouros fixos do vetor (ralos, lajes, vasos sanitários etc.).

A Sucen orienta que o trabalho do agente seja bimestral, realizado por quadra, com visitas em todos os imóveis. Nessa perspectiva, dificilmente os profissionais voltavam a fazer as visitas nos mesmos imóveis, o que impossibilitava estabelecer uma relação de confiança e vínculo com os moradores. A norma orienta, ainda, que tais atividades sejam executadas e registradas em instrumentos específicos da Sucen, posteriormente encaminhados para digitação centralizada na SMS (Sucen, 2001).

Dessa forma, a população reconhece o agente como o primeiro interlocutor para suas demandas e reclamações, requerendo dele a resolução de problemas que vão além da presença do vetor e da doença. O hiato entre as demandas da população e a resposta pública promove o descrédito da população quanto às competências do agente, comprometendo a sua atuação (Chiaravalloti e col., 2002). É pertinente admitir que diante desse quadro os ACV realizassem seus trabalhos de forma mecânica e repetitiva, causando a insatisfação tanto do profissional quanto do morador.

Com a descentralização das ações de vigilância preconizada pelo SUS e a inserção dos ACV nas UBS, com base na lógica da estratégia de saúde da família, foi criado um instrumento de registro denominado "histórico do imóvel”. Esse instrumento permitia o acompanhamento da situação encontrada no imóvel, bem como avaliar se havia mudanças no comportamento do responsável em relação às considerações feitas na visita anterior. Esse mesmo instrumento possibilitava avaliar os imóveis por situação de risco, facilitando o planejamento do trabalho e a priorização de visitas. Essa racionalidade no trabalho permitiu ao AS executar outras ações, além do controle preconizado pela Sucen, como atividades relacionadas a outros vetores que não o da dengue, orientações sobre o uso dos serviços de saúde, ações educativas em sala de espera das UBS, escolas e empresas, dentre outras (Aguiar, 2011).

Nesse processo, outros profissionais das UBS também elegiam prioridades que necessitavam de apoio dos agentes de saúde, as quais eram incluídas na rotina de trabalho. $O$ enfoque na ESF ampliou o olhar do AS sobre o território, o que se evidencia por algumas falas: o morador cumprimenta pelo nome a moça do postinho e não mais pela moça da dengue; ampliação das atividades para além do problema da dengue, somos verdadeiros multiplicadores de saúde; quando começamos a falar das atividades oferecidas nas UBS, percebemos a surpresa do morador, falando: "agora vocês estão fazendo isso também?". Para Mendes (1996) no processo de reconhecimento de um território é importante identificar, descrever e explicar os macroproblemas de saúde nele contidos, sempre referidos por atores portadores de um dado projeto de saúde, para depois articular, mediante a vigilância em saúde, um conjunto de operações intersetoriais destinadas a resolvê-los, tendo presente a disponibilidade real de recursos existentes nesse território.

Pesquisas realizadas apontam dificuldades e mesmo inviabilidade para o desenvolvimento das atividades de controle da dengue pelo fato de serem desenvolvidas verticalmente, sem seguir os princípios de descentralização do SUS (Santos, 2003). E também pela falta de integração das atividades do setor saúde com os demais setores, além da ausência de fluxos de encaminhamentos (Machado e Porto, 2003).

Por outro lado, o desenvolvimento de atividades na atenção básica com enfoque de vigilância em saúde contribuiu para o alcance de objetivos no que diz respeito às atividades de promoção a saúde, de prevenção das doenças e manejo ambiental, tornando viável uma prática centrada num conceito mais amplo de saúde (Brasil, 2009).

Nessa experiência foi necessária a manutenção 
dos supervisores como profissionais essenciais ao acompanhamento do trabalho no território e à realização da coordenação do trabalho conjunto na UBS. É possível que esse acompanhamento tenha possibilitado a melhora do trabalho da equipe na gestão da UBS e dos AS, bem como na busca de soluções para problemas intersetoriais.

As dificuldades e perspectivas positivas encontradas na integração dos AS com as ações da UBS podem ser percebidas pelas seguintes falas: no começo houve algumas alfinetadas, pois eram visões completamente diferentes para objetivos iguais, talvez o que precisa melhorar são as pessoas que sempre estão armadas, como se fossem para guerra, estamos em busca dos mesmos horizontes; hoje, depois de um tempo de desconforto e ansiedade, a aproximação aconteceu entre os AS e a UBS [...] $e$ há um melhor entendimento da população sobre o nosso trabalho; A proposta é interação com a comunidade, a saúde pública é isso, se não estaria dentro do hospital; Senti um maior crescimento, como profissional e maior responsabilidade, a equipe de AS e UBS tiveram uma interação que antes não havia e passei a observar mais a casa do morador, levando os problemas para as UBS, para uma possível resolução; Isso foi o pulo do gato, os ACV em AS, deixa a unidade mais redonda; Muitos moradores reclamam de alguns médicos e passamos para o enfermeiro, ou então dão sugestões de como poderia ser realizado determinada atividade na UBS de uma forma melhor.

Outra questão identificada nos registros foi a existência, por parte dos serviços responsáveis pelo controle de endemias, de uma percepção fragmentada dos problemas de saúde e sociais. Nessa perspectiva, a doença é entendida como um fenômeno isolado, reproduzida em laboratórios e controlada segundo normas científicas (Santos, 2003). Várias falas dos participantes apontam para essa fragmentação e modos de contorná-la: A incorporação do agente na UBS é trabalho de prevenção e é uma atenção básica; Não conhecíamos as atividades executadas na UBS, hoje não, orientamos e muitas vezes argumentamos porque funciona daquela forma; mudanças permitiram que o agente conhecesse as famílias e os problemas da população, o que ocasionou a melhora do vínculo com os moradores e da visão que os moradores têm dos agentes; aproveitar o trabalho do agente para conscientização das pessoas e não para recolher lixo; criar condições para que os agentes colaborem na organização da comunidade para solução de problemas comuns, reivindicações, prioridades coletivas. Outros exemplos de fragmentação das atividades de controle da dengue são encontrados nas normas técnicas e diretrizes da Sucen e do MS, como a realização de visitas bimestrais e de controle mecânico em todos os imóveis residenciais sem estabelecer prioridades dos imóveis de maior risco para a presença do vetor, e o não encaminhamento de soluções para o descarte definitivo de pneus e outros materiais inservíveis (Brasil, 1996, 2002).

Ao contrário das normas técnicas e diretrizes estabelecidas para o controle da dengue, a legislação que regulamenta o funcionamento do SUS aponta para a atenção integral à saúde, direcionando-o para uma prática que prioriza situações de maior vulnerabilidade, em que os serviços devem estar atentos às necessidades da população (Brasil, 1990). Além de tais aspectos, nos últimos anos a ocorrência de surtos e epidemias por doenças emergentes ou reemergentes vem colocando em pauta a necessidade de uma nova lógica de organização dos serviços de saúde (Brasil, 2009). A inserção dos AS nas UBS enquadra-se nessa nova lógica. No entanto, Campos (1997) alerta para o fato de que as questões de ordem econômica e política, muitas vezes, conduzem à proposição de normas, valores e estruturas que limitam a substituição de um modelo antigo por outro, novo.

De acordo com as normas da Sucen, a promoção e a prevenção estão centradas na figura dos profissionais de IEC (informação, educação e comunicação), que são responsáveis pela capacitação dos ACV e que definem as abordagens que devem ser realizadas nos imóveis, bem como as ações integradas de educação em saúde, comunicação e mobilização social. Nos municípios maiores é admitido o educador em saúde pública. Esses profissionais trabalham com a ideia subjacente de que as ações educativas serão incorporadas "naturalmente", transformando-se em uma prática cotidiana da população. Assim, as ações de educação em saúde são desenvolvidas de modo intuitivo, sendo fundamentadas no bom senso, sem a preocupação em criar espaços para o exercício de 
uma análise crítica pelos sujeitos envolvidos (Conversani, 2004).

Algumas falas dos participantes dos fóruns apontaram para a necessidade da descentralização das atividades educativas, de modo que essas não sejam prerrogativa dos IEC: Precisamos de capacitação; Necessitamos de novas informações para ampliar nossos conhecimentos e transmiti-los aos moradores, que também nos cobram métodos diferenciados, que poderiam ajudar na melhoria da saúde num todo...; Maior integração dos agentes com os trabalhos, quebra da vergonha de falar, participação nossa nos trabalhos. As falas mostram a necessidade de que os agentes, assim como os demais membros da equipe, devem se co-responsabilizar pela saúde da população da sua área de abrangência, necessitando, dessa forma, desenvolver ações de promoção e prevenção, seja nos domicílios ou nos demais espaços da comunidade (Brasil, 2009).

\section{Integralidade}

De uma maneira geral as unidades básicas de saúde sempre têm uma alta demanda de atendimentos do tipo queixa-conduta (Paim, 2002). A inserção dos agentes de saúde nas UBS aumentou, em muito, as solicitações por atendimentos diversificados, alterando a percepção dos profissionais sobre o que ocorria de fato no território. Isso acabou por gerar tensões e conflitos, pois, mesmo com as políticas de saúde apontando para a necessidade de reorganização do modelo de vigilância e atenção à saúde visando atender regulamentações sobre o funcionamento do SUS, os profissionais do município não estavam sensibilizados para essa mudança (Brasil, 1990).

Neste processo de transição se evidenciou a resistência dos profissionais das UBS em relação aos supervisores das equipes de controle da dengue e vice-versa. Isso criou dificuldades para a inserção dos AS, como pode ser notado nas seguintes falas: os agentes falam que nós, supervisores, não mandamos mais, que não seremos mais necessários, quem manda agora é a enfermeira; o supervisor precisa ter bom relacionamento, ser motivador; Tínhamos receio de como seríamos recebidos e as pessoas da unidade também [...] e trabalhamos isso em reunião [...] de repente, como passe de mágica, aconteceu [...] é uma coisa boa, todo mundo está integrado; hoje eles reconhecem que viemos para colaborar com a unidade; acredito que esta integração será para contribuir com a UBS [...] será em favor de nós todos.

Com base nos fatos, admite-se que a incorporação dos agentes de saúde nas UBS contribuiu para que as atribuições definidas para os profissionais pudessem ser executadas e assumidas de uma forma inovadora, com efetiva mudança na organização dos serviços de saúde e na perspectiva de ampliar a capacidade de resposta às necessidades básicas de saúde da população em sua área de abrangência. Tal configuração exige das UBS maior resolutividade dos problemas encontrados dentro de seu território e não se limitando ao modelo médico centrado na atenção clínica individual.

O AS, nesse novo contexto, passou a ter como um dos objetivos de sua atividade a atuação junto à comunidade: as atividades da unidade foram discutidas conosco em reunião; percebi que o morador me trata melhor depois que me viu na unidade e comecei a fazer as visitas de rotina; O morador ficou contente com o avanço e podemos ajudá-lo no acesso à unidade; Nós moramos e trabalhamos e detectamos ser gratificante levarmos um caso e conseguirmos resolver; $O$ agente é importante na visita domiciliar e em trabalhos educativos na comunidade; $\hat{E}$ difícil, complexo trabalhar na UBS [...] bate sentimentos, angústia, insatisfação, medo e cansaço; Existe a importância do trabalho em equipe [...] a unidade tem seu limite.

Esses achados coincidem com o que Costa e Carbone (2004) encontraram sobre o papel dos ACS na UBSF, que são considerados interlocutores privilegiados dos serviços com a comunidade, pois é por meio deles que a comunidade consegue espaço para se expressar. Existe urgência de mudanças e inovação nos paradigmas da saúde, com uma abordagem preventiva fundamentada em programas abrangentes de educação e de cuidado integral (Veras, 2007), tornando-os instrumentos de gestão pública que se aproxime cada vez mais da população e de suas reais necessidades (Oliveira, 2004).

Estimular a autonomia dos profissionais de saúde, principalmente em seu trabalho em equipe, é questão central para construir processos de trabalho mais efetivos; evitar a alienação decorrente da 
divisão do trabalho e manter a consciência do todo; adotar normas flexíveis que não inibam a criatividade da equipe; estimular, também, a autonomia dos usuários, incentivando-os para o autocuidado, oferecendo informações sobre os processos de adoecimento e o papel dos serviços de saúde na preservação da saúde, aumentando a consciência sanitária (Silva Jr., 2002).

\section{Intersetorialidade}

A intersetorialidade tem como base o reconhecimento do território, a identificação dos macroproblemas de saúde e a definição de um conjunto de operações intersetoriais destinadas a resolvê-los, tendo presente a disponibilidade real de recursos existentes nesse território. Ela se baseia na articulação das ações de governo sobre problemas concretos, identificados a partir das prioridades das pessoas que vivem nesses territórios, e que são transformadas em demandas políticas. Esse é o papel central que a prática da vigilância em saúde deve desempenhar. A falta de uma visão global pode levar ao desconhecimento e à manutenção da exclusão social ou o negligenciamento de processos saúde-doença emergentes ou latentes (Mendes, 1996).

Baglini e colaboradores (2005) desenvolveram no município de São José do Rio Preto um estudo qualitativo sobre as atividades de controle à dengue na visão de seus agentes e da população atendida, mostrando que ambos, ACV e ACS, não estavam preparados para lidar com questões relacionadas a problemas da coletividade e com a intersetorialidade. Situação semelhante foi detectada na Região Metropolitana de São Paulo, onde os ACS não tinham respaldo das UBSF para enfrentamento de questões relacionadas ao ambiente (Ianni e Quitério, 2009). Essa é uma questão que, segundo McMichael e Haines (1997), necessita de aprofundamento teórico e ampliação de conhecimentos, pois em muitos casos os problemas são novos, apesar de já inseridos na vida cotidiana da maioria das populações.

No caso do presente estudo, o supervisor da equipe recebia as demandas dos ACV e só existiam fluxos dentro da própria SMS, um fluxo intrasetorial. As questões que demandavam ações intersetoriais, aquelas relativas a outros setores do serviço pú- blico, eram encaminhadas para a coordenação do programa. Uma queixa constante dos agentes era de que quando realizavam as visitas domiciliares e se comprometiam em solucionar determinado problema havia uma morosidade na resolutividade. E, às vezes, o problema ficava sem solução: "falta de resolução de problemas encontrados desmotiva o trabalho"; precisa de melhoria da credibilidade junto ao morador maior resolutividade para os problemas encontrados; Criar condições para que os agentes colaborem na organização da comunidade para solução de problemas comuns, reivindicações, prioridades coletivas; ter mais experiências em trabalho na comunidade, potencializando o ser profissional.

Observamos, no decorrer do processo de inserção do AS, que seus supervisores acabavam desempenhando as funções de facilitadores na coordenação do trabalho, buscando realizar ações intersetoriais vinculadas à unidade de saúde.

De acordo com a Portaria GM/MS 2.488, de 21/10/2011 (Brasil, 2011), a atenção básica tem como fundamentos desenvolver relações de vínculo e responsabilização entre as equipes e a população. Desse modo, as equipes de saúde estarão investindo na transformação da relação dos indivíduos com os condicionantes socioambientais que propiciam o desenvolvimento de doenças e, também, pretendem trabalhar o conceito de cidadania e autonomia dos sujeitos, com vistas à modificação e melhoria de suas vidas (Brasil, 2009).

O supervisor pode ser um ator-chave nesse processo, a ser potencializado na articulação intersetorial dentro de suas áreas de abrangência ao invés de exercer a sua função de forma fiscalizadora e autoritária; pode vir a ter um bom relacionamento interpessoal e ser um motivador da equipe.

\section{Valorização do agente de saúde}

As doenças causadas por patógenos veiculados por vetores estão diretamente relacionadas à precariedade de condições sociais e sanitárias. $\mathrm{O}$ atual programa de controle não abrange políticas públicas voltadas para a solução da grave desigualdade relativa a tais condições, tornando ineficientes as medidas de promoção, de vigilância e de educação em saúde. Um exemplo disso aconteceu na área de 
abrangência de uma UBSF, na qual se iniciou o trabalho de controle à dengue e uma das ACS relatou a seguinte dificuldade: não adianta a equipe se preocupar em fazer a promoção e prevenção à dengue sem resolver esta prioridade da população (a coleta de lixo, que não disponível). Os agentes também se referiram a algumas falas da população presenciadas durante o desenvolvimento de suas atividades de rotina, antes de tornarem-se AS, como, por exemplo: você de novo, já sei tudo sobre dengue; a culpa é da população, que é porca; que adianta eu cuidar se o vizinho não cuida?; sabe o que tem que fazer, mas não faz [...] preguiça, quer que alguém faça por ele; minha casa é limpinha, não tem dengue. Valla e colaboradores (1993) revelam o fenômeno da "culpabilização da vítima” e mostram que a população tem dificuldade de acesso às informações oficiais, o que impossibilita que os grupos populares tenham uma visão abrangente sobre os determinantes de suas condições de vida e trabalho (Silva Jr., 2002).

A simples passagem de informação, ou conhecimento técnico, não implica em mudanças de hábito com reflexos na situação do domicílio, como a eliminação ou pelo menos a diminuição do número de recipientes que possam ser favoráveis à proliferação de vetores dos vírus da dengue (Gordon, 1988; Winch e col., 1991; Chiaravalloti-Neto, 1997). As atitudes dos sujeitos para alcançarem seus objetivos variam de acordo com os significados e a importância relativa atribuída aos diferentes bens, materiais e simbólicos, que reivindicam (Sader, 1988; Certeau, 1994). Assim, para que mudanças ocorram, há a necessidade de uma nova forma de olhar para as classes populares, principalmente no que se refere à nossa compreensão sobre suas maneiras de conhecer e agir no mundo (Valla, 1996, 1998).

Após a inserção dos agentes nas UBS ocorreram mudanças de percepção quanto à sua atuação junto aos moradores: agora não falamos só sobre a dengue [...] falamos sobre outras coisas, pois cansa repetir as mesmas coisas. Com isso a gente fica mais motivado e menos cansativo; valorizar cada serviço, cada coisa, um precisa conhecer o que o outro faz para integrar o trabalho; conquistamos nossa valorização, crescemos e agora não somos catadoras de lixo.

Os AS relataram boa relação com a comunidade, sentindo-se valorizados por participarem da equipe de saúde, por terem voz no planejamento das ações de saúde e, mais motivados, realizarem seu trabalho buscando soluções para as prioridades e demandas da comunidade. Como agentes, reconhecem que não tiveram formação suficiente na área de saúde e sentem necessidade de mais capacitação para assumirem a perspectiva do cuidado integral dos moradores; referem também o aumento de suas responsabilidades e a preocupação com a qualidade do seu trabalho.

\section{Educação permanente}

A educação permanente consiste num processo pedagógico que facilita o aprendizado, atualiza conhecimentos e habilidades, desenvolve competências de gestão e de cuidado na atenção básica, partindo dos problemas e desafios enfrentados no processo de trabalho e envolvendo práticas que possam ser definidas por múltiplos fatores: conhecimento, valores, relações de poder, planejamento e organização do trabalho, dentre outros. Importante é que devem ser considerados os elementos que façam sentido para os sujeitos envolvidos, sendo assim, uma aprendizagem significativa.

Esse processo educativo possui como pressuposto a programação ascendente; parte da análise coletiva dos processos de trabalho, levantando os nós críticos a serem enfrentados na atenção e/ou na gestão, e estimula a construção de estratégias contextualizadas que promovam o diálogo entre as políticas gerais e a singularidade dos lugares e das pessoas, possibilitando o desenvolvimento de experiências inovadoras na gestão do cuidado e dos serviços de saúde (Brasil, 2011). Considerando-se que integração não é acomodação, ela resulta da capacidade de ajustar-se à realidade, acrescida da possibilidade de transformá-la (Freire, 2003).

Os temas educação na saúde, educação comunitária, participação popular, educação participativa e educação permanente vêm cada vez mais ocupando espaço nas discussões e reflexões dos profissionais de saúde pública, como uma das diretrizes para a concretização e reestruturação do SUS. A educação na saúde pode ser entendida como um conjunto estruturado de práticas pedagógicas articuladas às práticas de saúde; dialógica, que se dá nas relações 
entre sujeitos sociais que portam diferentes saberes e em diferentes espaços, públicos ou privados, podendo ser apresentada de maneira formal ou informal, utilizando-se metodologias progressistas ou conservadoras (Freire, 1982; Pedrosa, 2001).

O MS, por meio da Portaria n ${ }^{0}$ 2.488, de 21/10/2011, descreve as atribuições dos profissionais da atenção básica e também dos agentes que devem desenvolver atividades de promoção da saúde, de prevenção das doenças e dos agravos e de vigilância à saúde por meio de visitas domiciliares e de ações educativas individuais e coletivas nos domicílios e na comunidade (Brasil, 2011).

Na prática, os AS sentem necessidade de capacitação para o trabalho na perspectiva da integralidade do atendimento, o que se expressa nas seguintes falas: saber orientar a comunidade; integração do grupo e discutir o desempenho de cada um; os fóruns servem para aumentar a união da equipe dos AS em relação à UBS; Conhecer o trabalho feito nas outras unidades que não tínhamos contato; Melhor entendimento sobre o processo de trabalho, uniformização das informações; os fóruns contribuíram para o nosso desenvolvimento, tanto pessoal como profissional; Vivência de experiências novas e opiniões diferentes.

Conforme o relato dos AS, os fóruns contribuíram para a reorientação do modelo de atenção à saúde, criando um espaço de discussão onde o saber e o fazer, num processo de educação permanente, foram incorporados à prática concreta dos serviços de saúde (Freire, 200o). A educação permanente deve ser constitutiva da qualificação das práticas de cuidado, gestão e participação popular. Nesse sentido, a educação permanente é educação no trabalho, pelo trabalho e para o trabalho nos diferentes serviços, cuja finalidade é melhorar a saúde da população (Brasil, 2011).

Os fóruns foram realizados nessa perspectiva, partilhando ideias e métodos que visaram estimular a tomada de posição e que objetivaram possibilitar ao educando - os profissionais de saúde - emitir suas opiniões, discutir aspectos positivos e negativos, as dimensões sociais, políticas, éticas, culturais, econômicas, entre outras, caminhando para a formação de sujeitos capazes de pensar e propor processos de transformação social (Gomes e Casagrande, 2002).

\section{Conclusões e considerações finais}

Essa pesquisa mostrou a possibilidade da construção de um novo modelo de gestão do SUS municipal. A experiência permitiu otimizar recursos e contribuiu para a melhoria das relações entre trabalhadores e usuários e entre os próprios trabalhadores da equipe de saúde para o controle da dengue, bem como outras situações identificadas no território. Também possibilitou identificar aspectos importantes do processo de descentralização das ações de controle da doença, que, neste caso, se expressou pela inserção dos AS na atenção básica do município de São José do Rio Preto. Segundo as categorias consideradas no estudo, os principais aspectos identificados foram:

- Inserção social: o agente, que só trabalhava com a prevenção e o controle da dengue ampliou seu olhar em relação a outros problemas que afetam diretamente a saúde da comunidade;

- Integralidade: essa experiência ampliou o olhar do agente, que passou a ver a família, a situação do imóvel e do ambiente que o circunda como um todo, bem como a totalidade da área de abrangência da comunidade sob sua responsabilidade;

- Intersetorialidade: é um desafio que persiste. Entretanto, a incorporação dos AS às equipes das UBS facilitou a busca das soluções desses problemas, reforçando a importância do seu papel na equipe e aumentando a credibilidade do agente frente ao morador.

- Valorização do AS: eles relataram a melhora da relação com a comunidade, sentindo-se valorizados por participar da equipe de saúde e por terem voz no planejamento das ações de saúde, e motivados para realizarem seu trabalho, buscando soluções para as prioridades e demandas da comunidade. Como agentes, reconhecem que não tiveram formação suficiente na área de saúde e sentem necessidade de mais capacitação para contribuírem com um cuidado integral aos moradores; referem também o aumento de suas responsabilidades e a preocupação com a qualidade do seu trabalho.

- Educação permanente: os fóruns de discussão permitiram aos participantes emitir suas opiniões, discutir aspectos positivos e negativos das 
dimensões sociais, políticas, éticas, culturais e econômicas do seu trabalho, caminhando para a formação de profissionais mais capacitados a pensar, rompendo clássicos paradigmas da Sucen, na perspectiva de viabilizar os princípios e diretrizes de acesso universal e da integralidade do SUS, e uma prática centrada num conceito ampliado de saúde.

A experiência da integração dos AS/Sucen na AB/UBS de São José do Rio Preto vai ao encontro das diretrizes do SUS. O estudo de caso mostrou que essa é uma possibilidade a ser considerada no controle da dengue, podendo contribuir para evitar a fragmentação decorrente da forma como os serviços de controle de endemias encaram esse problema, atualmente. Além de tais aspectos, esses agentes podem ser profissionais que portem um olhar ampliado, não focado somente no agravo, merecendo por isso mais reconhecimento e melhores condições de trabalho. Os fóruns, como ferramenta de educação permanente, mostraram-se uma estratégia interessante de gestão, que pode vir a ser replicada em outras cidades que apresentam problemas similares aos do município estudado, São José do Rio Preto, tendo em vista a reorganização do sistema de saúde municipal.

\section{Colaboração dos autores}

Cesarino participou do desenvolvimento dos fóruns, redação das falas, análise das falas e redação do artigo. Ferraz e Vicentini colaborou com o desenvolvimento dos fóruns e redação do artigo. Ianni e Chiaravalloti-Neto fizeram a análise das falas e redação do artigo. Dibo coordenou as atividades, análise das falas e redação do artigo.

\section{Referências}

AGUIAR, Z. N. SUS: Sistema Único de Saúde: antecedentes, percurso, perspectivas e desafios. São Paulo: Martinari, 2011.

APM - ASSOCIAÇÃO PAULISTA DE MEDICINA. SUS: o que você precisa saber sobre o Sistema Único de Saúde. São Paulo, 2001.
BAGLINI, V. et al. Atividades de controle do dengue na visão de seus agentes e da população atendida, São José do Rio Preto, São Paulo, Brasil. Cadernos de Saúde Pública, Rio de Janeiro, v. 21, n. 4, p. 1142-1152, 2005.

BARBAN, E. G.; OLIVEIRA, A. A. O modelo de assistência da equipe matricial de saúde mental no Programa Saúde da Família do município de São José do Rio Preto (capacitação e educação permanente aos profissionais de saúde na atenção básica). Arquivos de Ciência e Saúde, São José do Rio Preto, v. 14, n. 1, p. 52-63, 2007.

BARDIN, L. Análise de conteúdo. 7o. ed. Lisboa: Persona, 1977.

BRASIL. Lei no 8.08o, de 19 de setembro de 1990. Dispõe sobre as condições para a promoção, proteção e recuperação da saúde, a organização e o funcionamento dos serviços correspondentes e dá outras providências. Diário Oficial da União, Brasília, DF, 20 set. 1990. Seção 1, p. 18055.

BRASIL. Ministério da Saúde. Manual de vigilância epidemiológica da dengue. Brasília, DF, 1996.

BRASIL. Ministério da Saúde. Fundação Nacional de Saúde. Dengue: instruções para pessoal de combate ao vetor. Brasília, DF, 2001. (Manual de Normas Técnicas).

BRASIL. Ministério da Saúde. Programa Nacional de Controle da Dengue (PNCD). Brasília, DF, 2002.

BRASIL. Ministério da Saúde. Vigilância em saúde: zoonoses. Brasília, DF, 2009.

BRASIL. Ministério da Saúde. Portaria MS/GM n ${ }^{0}$ 2.488, de 21 de outubro de 2011. Aprova a Política Nacional de Atenção Básica, estabelecendo a revisão de diretrizes e normas para a organização da Atenção Básica, para a Estratégia Saúde da Família (ESF) e o Programa de Agentes Comunitários de Saúde (PACS). Diário Oficial da União, Brasília, DF, 21 set. 2011. Seção 1, p. 48-55.

CAMPOS, G. W. S. Considerações sobre a arte e a ciência da mudança: revolução das coisas e reforma das pessoas: o caso da saúde. In: CECÍlIO, L. C. O. (Org.). Inventando a mudança na saúde. 2. ed. São Paulo: Hucitec, 1997. p. 29-88. 
CERTEAU, M. A invenção do cotidiano. Petrópolis:

Vozes, 1994.

CHIARAVALLOTI, V. B. et al. Avaliação sobre a adesão às práticas preventivas do dengue: o caso de Catanduva, São Paulo, Brasil. Cadernos de Saúde Pública, Rio de Janeiro, v. 18, n. 5, p. 13211329, 2002.

CHIARAVALLOTI-NETO, F. Descrição da colonização de Aedes aegypti na região de São José do Rio Preto, São Paulo. Revista da Sociedade Brasileira de Medicina Tropical, Uberaba, v. 30, n. 4, p. 279-285, 1997.

CHIARAVALLOTI-NETO, F. et al. Controle do dengue em uma área urbana do Brasil: avaliação do impacto do Programa Saúde da Família com relação ao programa tradicional de controle. Cadernos de Saúde Pública, Rio de Janeiro, v. 22, n. 5, p. 987-997, 2006.

CHIARAVALLOTI-NETO, F. et al. Programa de controle do dengue em São José do Rio Preto, São Paulo, Brasil: dificuldades para a atuação dos agentes e adesão da população. Cadernos de Saúde Pública, Rio de Janeiro, v. 23, n. 7, p. 16561664, 2007.

CONVERSANI, D. T. N. Uma reflexão crítica sobre a educação em saúde. Boletim do Instituto de Saúde, São Paulo, v. 34, p. 4-5, dez. 2004.

COSTA, E. M. A.; CARBONE, M. H. Saúde da família: uma abordagem interdisciplinar. Rio de Janeiro: Rubio, 2004.

ESTRELA, W. L. Relatório sobre a formação de médicos homeopatas para o SUS. Revista de Homeopatia, São Paulo, v. 73, n. 3/4, p. 46-5o, 2010.

EVANGELISTA, S. S. M. et al. Fórum Nacional da SBACV: o desafio do pé diabético. Cirurgia Vascular \& Angiologia, São Paulo, v. 15, p. 29-32, dez. 1999.

FREIRE, P. Ação cultural para a liberdade e outros escritos. 6. ed. Rio de Janeiro: Paz e Terra, 1982.

FREIRE, P. Educação como prática de liberdade: a sociedade brasileira em transição. Rio de Janeiro: Paz e Terra, 200o.
FREIRE, P. Pedagogia da autonomia: saberes necessários à prática educativa. 25. ed. São Paulo: Paz e Terra, 2003.

GOMES, J. B.; CASAGRANDE, L. D. R. A educação reflexiva na pós-modernidade: uma revisão bibliográfica. Revista Latino-Americana de Enfermagem, Ribeirão Preto, v. 10, n. 5, p. 696-703, 2002.

GORDON, A. J. Mixed strategies in health education and community participation: an evaluation of dengue control in the Dominican Republic. Health Education Research, Oxford, v. 3 , n. 4, p. 399-419, 1988.

IANNI, A. M. Z.; QUITÉRIO, L. A. D. A questão ambiental urbana na atenção básica e o PSF. In: COHN, A. (Org.). Saúde da família e SUS: convergências e dissonâncias. São Paulo: Cedec, 2009. p. 113-140.

LIMA, E. C.; VILASBÔAS, A. L. Q. Implantação das ações intersetoriais de mobilização social para o controle da dengue na Bahia, Brasil. Cadernos de Saúde Pública, Rio de Janeiro v. 27, n. 8, p. 15071519, 2011.

MACHADO, J. M. H.; PORTO, M. F. S. Promoção da saúde e intersetorialidade: a experiência da vigilância em saúde do trabalhador na construção de redes. Epidemiologia e Serviços de Saúde, Brasília, DF, v. 12, n. 3, p. 121-130, 2003.

McMICHAEL, A. J.; HAINES, A. Global climate change: the potential effects on health. British Medical Journal, London, v. 315, n. 7111, p. 805809, 1997.

MENDES, E. V. Uma agenda para a saúde. São Paulo: Hucitec, 1996.

MONDINI, A. et al. Análise espacial da transmissão de dengue em cidade de porte médio do interior paulista. Revista de Saúde Pública, São Paulo, v. 39, n. 3, p. 444-451, 2005.

OLIVEIRA, F. J. F. A Programação Pactuada e Integrada (PPI) no contexto da Norma de Assistência à Saúde (NOAS) e o Conselho Nacional de Saúde: uma discussão sobre a gestão do SUS. 2004. Dissertação (Mestrado em Gestão em Saúde) - Escola Nacional de Saúde Pública Sergio Arouca, Rio de Janeiro, 2004. 
PAIM, J. S. Saúde: política e reforma sanitária. Salvador: Instituto de Saúde Coletiva, 2002.

PEDROSA, L. I. S. Avaliação das práticas educativas em saúde. In: VASCONCELLOS, E. M. A saúde nas práticas e nos gestos: reflexão da rede de educação. São Paulo: Hucitec, 2001. p. 261-281.

PENNA, M. L. F. Um desafio para a saúde pública brasileira: o controle do dengue. Cadernos de Saúde Pública, Rio de Janeiro, v. 19, n. 1, p. 305309, 2003.

SADER, E. Quando novos personagens entraram em cena: experiências, falas e lutas dos trabalhadores da Grande São Paulo (1970-80). São Paulo: Paz e Terra, 1988.

SANTOS, L. Avaliação das ações de controle da dengue: aspectos críticos e percepção da população: estudo de caso em um município do Nordeste. 2003. Dissertação (Mestrado em Saúde Pública) - Centro de Pesquisas Aggeu Magalhães da Fundação Oswaldo Cruz, Recife, 2003.

SILVA JR., E. A. Manual de controle higiênico sanitário em alimentos. 5. ed. São Paulo: Varela, 2002.
SUCEN - SUPERINTENDÊNCIA DE CONTROLE DE ENDEMIAS. Vigilância e controle de Aedes aegypti: normas, orientações e recomendações técnicas: plano de intensificação das ações de controle de dengue no Estado de São Paulo. São Paulo: Secretaria da Saúde. Governo do Estado de São Paulo, 2001.

VALLA, V. V. A crise de interpretação é nossa: procurando compreender a fala das classes subalternas. Revista de Educação \& Realidade, Porto Alegre, v. 21, n. 2, p. 177-191, 1996.

VALLA, V. V. Apoio social e saúde: buscando compreender a fala das classes populares. In: COSTA, M. V. (Org.). Educação popular hoje. São Paulo: Loyola, p. 151-179, 1998.

VALLA, V. V.; CARVALHO, M.; ASSIS, M. Participação popular e os serviços de saúde: 0 controle social como exercício da cidadania. Rio de Janeiro: Fiocruz, Escola Nacional de Saúde Pública, 1993.

VERAS, R. Envelhecimento populacional e as informações de saúde do PNAD: demandas e desafios contemporâneos: introdução. Cadernos de Saúde Pública, Rio de Janeiro, v. 23, n. 10, p. 2463-2466, 2007.

WINCH, P. et al. Beliefs about the prevention of dengue and other febrile illnesses in Merida, México. Journal of Tropical Medicine \& Hygiene, Deerfield, v. 94, n. 6, p. 377-387, 1991. 